\title{
Determinants of User Intention in Using e-Learning Technology in Indonesian Context: An Empirical Study
}

\author{
Amri Tanduklangi \\ Senior Lecturer, Postgraduate Study of Management \& \\ Faculty of Education, Halu Oleo University
}

Doi:10.5901/mjss.2017.v8n3p69

\begin{abstract}
At present, through the help of the internet, an increasing number of higher education institutions worldwide encourages faculty and students to adopt e-Learning in spite of the many barriers still exists in its implementation. This study presents how organizational factors and ease of use influence perceived usefulness and intention to use e-Learning. For this purpose, three hundred and ninety four samples collected from students of seven higher institutions in Southeast Sulawesi of Indonesia were surveyed with a questionnaire to validate the proposed framework through their own perceived behaviors. The result of the analysis using structural equation modeling of SmartPLS 2.0 shows that organizational culture, and perceived ease of use is positively related to both Perceived Usefulness and Intention to Use e-Learning. In addition, Organizational Support shows a significant effect on Intention to Use e-Learning, but a weak effect on Perceived Usefulness of e-Learning.
\end{abstract}

Keywords: Internet; e-Learning; Organizational Support and Culture; Perceived Ease of Use and Usefulness; Intention to Use

\section{Introduction}

The use of computers, web technology over the internet gives a variety of convenience and great opportunities to an organization with their employees and clients for the evolving rapidly. Employees and clients including academic staff, students, administrative staff of a college requires adjustments of knowledge and new technologies and change their behavior to develop new skills. So that the procurement and use is increasingly contributing to the achievement of the dissemination of knowledge and the transfer of knowledge through e-Learning. A recent study conducted by (Tanduklangi, Alberth, \& Amri, 2014) found that teaching writing under web instruction has a significant impact on students writing achievement. They also found that perceived usefulness and user acceptance have positive associations with student achievement.

Previous studies regarding the perception of acceptance of information technology, which have contributed to the development of systems that exist at the present time, among others, is a very famous theory of technology acceptance model (TAM) proposed by Davis (1986), which was developed from the Theory of Reasoned Action by (Fishbein \& Ajzen, 1975). The Davis' theory proposes that user motivation can be explained by three factors, namely perceived ease of use, perceived usefulness, and attitude towards using. A number of researchers have added other factors to technology acceptance theory. For example, (Hartwick \& Barki, 1994) introduce subjective norm, perceived behavioral control, and self-efficacy. Essential and other relevant factors regarding the acceptance of e-Learning technology is the absorption capacity and the implementation of e-Learning technologies.

The absorption capacity is the ability to recognize the values of the new, external information, and the ability to apply it, (Njenga, 2011). It was found that the culture of the organization (in response to the change, communication and absorptive capacity) affects the acceptance of e-Learning technologies (Njenga, 2011). A positive relationship between perceived ease of use and perceived usefulness echoed by some researchers like (Shen \& Eder, 2010); (Brown, 2002); (Melas C. D., Zampetakis, Dimopoulou, \& Moustakis, 2011); (Chen, Wang, Murman, Olaniran, \& Chen, 2012) (Yen, Wu, Cheng, \& Huang, 2010); (Roca \& Gagne, 2008); (Liao \& Liu, 2011). In relation to the use of e-Learning, for example, a 
study was conducted in a Malaysian college to seek an e-Learning acceptance by using the TAM model made by (Masrom, 2007). The result shows the perceived ease of use has a significant relationship to perceived usefulness. Subsequent findings that perceived ease of use has a positive effect on the perceived usefulness of a study concerning the intention in the use of e-Learning hospital employees in Taiwan (Chuo Y.-H. , Tsai, Lan, \& Tsai, 2011). Moreover, perceived ease of use has a positive influence on the perceived usefulness of the use of blended learning by students of the University of Patras, Greece (Melas C. D., Zampetakis, Dimopolou, \& Moustakis, 2011). Also in the same year, it was found perceived ease of use has a positive effect on the perceived usefulness of e-Learning employees of telecommunications companies in Taiwan (Chuo Y.H. Tsai, Lan, \& Tsai, 2011).

However, the relationship of perceived ease of use and perceived usefulness to the intention is still being debated among researchers of acceptance of information technology. A positive relationship was stated by a number of other researchers (Melas C. D., Zampetakis, Dimopolou, \& Moustakis, 2011); (Yen, Wu, Cheng, \& Huang, 2010); (Masrom, 2007) and (King \& He, 2006). Among other things, there is a direct effect of perceived usefulness on intention to use $e-$ Learning of the students (Rezaei, Mohammadi, Asadi, \& Kalantary, 2008). Perceived usefulness directly affects the intention to use, weaker, but still has an acceptable path coefficient (Saade, 2003). Perceived usefulness and perceived ease of use has a positive influence on behavioral intention to study acceptance of e-Learning tools (Lee, 2006); (Moon \& Kim, 2001). Moreover, perceived usefulness and perceived ease of use has a positive influence on the behavioral intention to use e-Learning company employee's telecommunications in Taiwan (Chuo Y.-H. , Tsai, Lan, \& Tsai, 2011). Instead, there are a number of findings which found no significant relationship between perceived usefulness and perceived ease of use on behavioral intention to study technology acceptance of Korean students. However, perceived usefulness has insignificant effect on behavioral intention to use blended learning by students (Park, 2009)

Criticism towards previous cultural studies in which these studies tend to simplify their concept by using the concept of state culture (national culture) that does not necessarily measure actual culture (Harju, 2007). Therefore, with dynamic changes in the environment, in addition to cultural factors, elements of organizational and technological support are also an important issue that motivates researchers to conduct this study because every organization and individual has its own level of acceptance and management skill in e-Learning. Acceptance and management capacity in the form of policy support from high level rank officials of the colleges in the form of programs and activities that support the use of e-Learning requires an in depth study. It is because, an increasing number of higher education institutions in Indonesia have made use of information and communication technologies, especially e-Learning based academic services to support for better quality, but most of the others, especially higher institutions in the eastern region including Southeast Sulawesi still have gaps in some respects, particularly with regard to factors, such as organizational support, technology and culture in the use of e-Learning. On the basis of these gaps, the objective of the current study was to determine the influence of organizational support, organizational culture, perceived ease, and perceived usefulness on intention in using e-Learning among students.

\section{Literature Review}

\section{$2.1 \quad$ E-Learning}

E-Learning is a general term for all the mechanisms used to aid teaching and dissemination of information through electronic media. E-Learning offers alternative methods to the stakeholders of education to not only use abundant resources that are nearby, but also offers potential and inexpensive resources to the student community. E-Learning offers the flexibility of place and time of the presentation and provides equal access to higher education institutions and students. Other than using private blogs, in this context, lecturers also have employed a couple of LMS such as Nicenet and Edmodo Learning Management Systems as medium of instructions. Lecturers rarely used e-Learning as a complete substitution of teaching and learning medium of instruction. Instead, they used it mostly in the mode of blended learning, meaning part of the instructional materials were presented through face to face classroom interactions, while the rest instructions were conducted through online mode of learning.

\subsection{Organizational Support}

The organizational support in this study is defined as the level of effort in promoting the college, educate, train and support the use of e-Learning is perceived by the subjects. In this study the researcher adopts (Igbaria, Zinatelli, Grag, \& Cavaye, 1997) who classify organizational support into three dimensions, namely: (1) management support, (2) education and training and computing support. The latter includes the promotion, technical assistance, manuals, books and 
helpdesk. According to them policy on organizational support will assist users in adopting an information system and accumulate knowledge and experience. For example, a good management can support increased resources, and encourages users to adopt an aggressive manner of information system.

\subsection{Organizational Culture}

Organizational culture is often called a corporate culture in which there are some elements that influence the acceptance of organizational innovation as part of a social system form. Organizational culture in the context of this study is built in three dimensions, i.e., response to change, attitudes towards communication and the ability to accept and apply knowledge as developed by (Njenga, 2011). Having practiced these dimensions, an organization is expected to be able to easily adopt a change, do an experiment, and build constructive communication that can bring about change.

\subsection{Perceived Ease of Use}

Perceived ease of use is the degree to which a person believes that using a system of e-Learning is easy, because the easiness is essential for the system of e-Learning. According to TAM theory, easy to use system will encourage someone to use the system. In the context of this study, Davis (1986) defines perceived ease as the degree to which people believe that using a particular system requires a little effort. Someone usually tries to minimize the effort in behavior. Similarly, (Ya-Chu \& Kuo-Hung, 2011) believe that users will form initial perception regarding the perceived ease of using a particular system based on their common beliefs pertaining to the system and its use. It is also believed that the perceived ease of innovation helps to reduce uncertainty and leads one to adopt the technology in answering questions (Elliott \& Fu, 2008). Moreover, according to (Porter \& Donthu, 2006) the user will avoid anything new because of the perception of the difficulties and risks associated with learning something.

\subsection{Perceived Usefulness}

Usefulness, according to Davis (1986) is a person's perception of the degree to which users or potential users believe that using a particular system can improve job performance and provide benefits to both organizations and individuals. In the context of e-Learning it is defined as the level of reliability, effectiveness, and cost effectiveness derived from technological innovation which is determined by its use. Therefore, the usefulness can be defined as the degree to which the innovation is considered better than the comparable that can be viewed from the standpoint of convenience, comfort, satisfaction, and accuracy. The effect of usefulness in explaining the behavior of individual intention to use technology is in line with expectancy theory proposed by (Davis, 1986) and (Davis \& Bagozzi, 1989) who believed that a person using a computer system because s/he expects to improve her or his performance.

\subsection{Conceptual Framework}

The TAM model proposed by Davis (1986) derived from the Theory of Reasoned Action (TRA), becomes one of the most widely used models in information systems, partly because it is easy to understand and simple. In relation to the acceptance of information technology, (Harju, 2007) suggests that if an organization is perceived as adaptive and is continuously seeking improvement, then it will generate a positive attitude towards the use of information technology to improve its activities. Hence, organizational culture is expected to reduce the level of resistance to change, and thereby gives the possibility for potential users to the underlying decision in using the system. In higher education institutions, support for the experimental use of learning technologies has a significant influence on its use. As it is believed that the culture of an organization that is responsive to the changes tends to be successful in adopting technology. Also, the ability to explain the organization's objectives clearly can contribute to helping students use information technology, especially e-Learning because communication is a nutrient that is essential in the process of change in an organization (Njenga, 2011).

Therefore, this research is done with the intention other than validating the factors that influence the intention that has been done by a number of previous researchers, is also intended to validate the integration of other factors into the TAM model, i.e., the organizational and cultural factors as seen in the following figure.

Thus, in this study framework, there are two main factors affect the intention of using e-Learning, the constructs of organizational factors include organizational support and organizational culture constructs and individual factors that include the construct of perceived ease of use, perceived usefulness and motivation to use. Both of these factors were 
tested empirically to validate its application in the theory of technology acceptance model of e-Learning as seen from the relationship between the constructs in the conceptual framework (Figur1). By combining organizational level constructs with individual constructs into technology acceptance model (TAM), Davis (1986), the model of the design of this study is expected to become a more comprehensive model that can predict the acceptance of e-Learning technologies, especially e-Learning technology acceptance model student in Southeast Sulawesi.

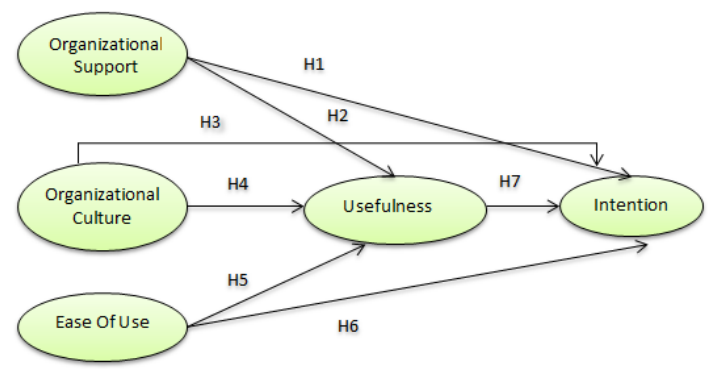

Figure 1: Research Conceptual Framework Model (Tanduklangi, 2014)

\section{Methods}

This is a correlation study because the research is intended to explain the important variables related to the problem. This study also sought to establish cause-and-effect relationship through correlation and regression analysis. In terms of time, the study is classified as a one-shot or cross-sectional study because the data was collected only once, in a certain period of time to meet the objectives of this study.

The methodology of this study is a survey related to the withdrawal of the subject from a population sample and to draw conclusions over population. The method used in this study is categorized into two parts, namely: (1) questionnaire which is a very important method of collecting primary data in this survey; (2) the statistical method that employed structural equation modeling (SEM) as the main technique for data analysis. The survey was conducted in three cities, namely the city of Kendari, Bau-Bau, and Kolaka with a total population of students of public and private universities throughout the Southeast Sulawesi province as many as 67.920 students (BPS [Central Bureau of Statistics] Indonesia, 2014).

\section{Results and Discussion}

\subsection{Outer Model (Model Measurements)}

The result of the second order confirmatory factor analysis shows loadings of all item indicators are above 0.5 and therefore these indicators were used to measure a variable (Ghozali \& Latan, 2012). Similarly, the value of AVE and commonality values for indicators of all constructs were above 0.50 so that it meets the requirements of convergent validity.

\subsection{Structural Model (Inner models)}

SmartPLS 2.0 was employed to examine the statistical significance of the relations in the model. The structural model shows path coefficients and $t$-value of relationships among constructs. Before performing the interpretation of the path coefficients, the first examination that is fit inner goodness of the model took place. The assessment can be seen from the values of $R^{2}$ for each endogenous variable in the structural equation (Solimun, 2004). The value of $R^{2}$ of each endogenous variable that shows the value of $R^{2}$ of the usefulness using e-Learning is equal to 0.628 . This means that the respondents' perception of the usefulness of using e-Learning is explained by the organizational support and organizational culture with $62.8 \%$. Furthermore, the value of $\mathrm{R}^{2}$ of endogenous variables of intention in using e-Learning is equal to 0.705 , meaning the Intention to Use is explained by the variance of Organizational Culture, Organizational Support, Usefulness, and Ease of Use with 70.5\%. Overall, the results of goodness of fit reflect that the research model has a good fit. 


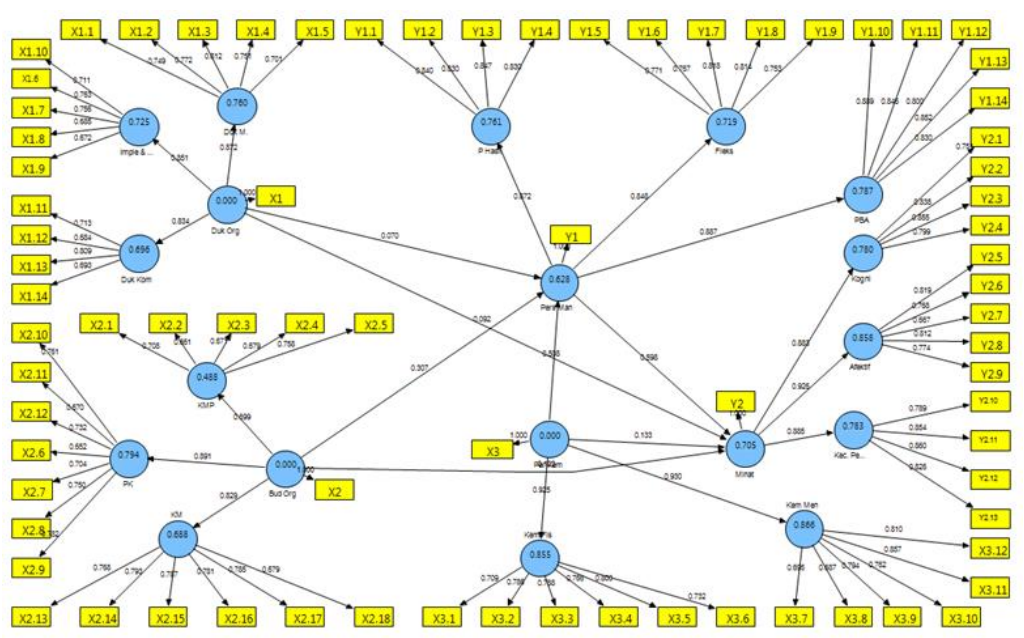

Figure 2: E-Learning acceptance model

Furthermore, examination of the inner workings of the model goodness of fit was also performed with a value of $\mathrm{Q}^{2}$ predictive relevance to measure the ability of the model to predict. The Predictive Value relevance is calculated by the following formula:

$$
Q^{2}=1-\left(1-R^{2}\right)\left(1-R^{2} 2\right) \ldots\left(1-R^{2} p\right)
$$

After having calculated its predictive value relevance, the result shows

$$
\begin{aligned}
& Q^{2}=1-(1-0.628)(1-.705) \\
& =1-(0.372)(0.295)
\end{aligned}
$$$$
=1 \text { to } 0.10974
$$$$
=0.89026
$$

This result indicates that this model is in very good category, which is able to predict the acceptance model of $e$ Learning as much as $89 \%$, while the rest $(11 \%)$ is explained by other variables which are not included in the model. The acceptance model of e-Learning with the proposed TAM development is illustrated in Fig, 2.

Based on the statistical $t$-test table (Sugiyono, 2009) and the seventh hypothesis testing results, as seen in Table 1, there are five hypotheses that have ties at the 0.01 level, namely, $\mathrm{H3}, \mathrm{H} 4, \mathrm{H} 5, \mathrm{H} 6$ and $\mathrm{H} 7$; one hypothesis that has a relationship to the level of 0.05 i.e., $\mathrm{H} 1$. While the other hypothesis that is $\mathrm{H} 2$ shows a weak path coefficient value, with a significant level at 0.20 . So overall, only one hypothesis concerning the technology acceptance model of e-Learning is rejected at 0.5 margin error, while the six other hypotheses are accepted.

\subsection{Hypothesis Testing}

Table 1: Summary of Hypothesis Testing E-Learning Acceptance Model Student

\begin{tabular}{|l|l|l|l|}
\hline Hypothesis & Influence & Path coefficients (t-values) & The results (95\%) \\
\hline H1 & Organizational Support -> Intention & $0.133(2.102)^{*}$ & Accepted \\
H2 & Organizational Support -> Usefulness & $0.069(1.259)+$ & Rejected \\
H3 & Organizational Culture -> Intention & $0.286(4.026)^{* *}$ & Accepted \\
H4 & Organizational Culture -> Usefulness & $0.306(4.773)^{* *}$ & Accepted \\
H5 & Ease of Use -> Usefulness & $0.508(10.111)^{* *}$ & Accepted \\
H6 & Ease of Use -> Usefulness & $0.436(8.710)^{* *}$ & Accepted \\
H7 & Usefulness -> Intention & $0.598(11.818)^{* *}$ & Accepted \\
\hline + Significant at the 0.20 level & & \\
* Significant at the 0.05 level & & \\
** Significant at the level of 0.01 & & \\
\hline
\end{tabular}

Source: Results of the processed primary data using SmartPLS, 2014 
This empirical study shows that the formulated six out of seven hypotheses are similar to that hypothesized in the study, while the other one is not the same. The findings of this study indicate that there is an influence of the organizational support on intention, while the effect on the perception of organizational support on usefulness is significant but weak. Ease of use and the usefulness as well as usefulness in using e-Learning and the intention in e-Learning exert the strongest influence. Then, followed by the relationship between organizational culture and the usefulness of using $e-$ Learning and between organizational culture and usefulness of using e-Learning.

The results show the $R^{2}$ for the endogenous variables of the usefulness of using e-Learning is 0.649 and for the endogenous variables of intention is at 0713 , while the value of Predictive Relevance $\left(Q^{2}\right)$ (accepted prediction model) is at $89 \%$. The acceptance model developed through this study is a more comprehensive model with the inclusion of organizational culture and organizational support that become critical factors of the acceptance of e-Learning in Southeast Sulawesi. It was found that cultural factors have a moderate effect in relation to the perception of the usefulness of using e-Learning and intention of using e-Learning. Meanwhile, the research also shows a hard impact of organizational support on the intention, but has a little impact on the usefulness of using e-Learning at the confidence level of 0.05 .

\section{Discussion}

\subsection{Influence of Organizational Support on Intention}

The result of the current study demonstrates that organizational support exerts a positive and significant influence on Intention in Using e-Learning. This finding indicates that the organizational support including management, training as well as the availability of computer and internet connection affect the intention of using e-Learning. The result is consistent with the results of a study which was conducted by (Macharia \& Nyakwende, 2010). The research results proved empirically by a multiple regression analysis, which shows that organizational support and availability of ICT influence the desire to adopt a learning management system (e-Learning). This study suggests that the readiness of the organization plays an important role in the implementation of effective e-Learning. A survey over professors of public and private universities in Kenya also shows that the effect of this factor is statistically significant and explained by $35 \%$ of the variance of intention in using e-Learning. As a community of fellow developing countries, large-scale use of e-Learning at the community colleges in Southeast Sulawesi is still at a minimum due to limited financial support for the network costs, such as the cost of hiring Internet bandwidth. In disregard, (Chen, Shang, Yu Hou, \& Humaour, 2012) argue that if the information system is supported by the leaders of the institution, then the user will feel positive. Another survey over the academic staffs, which was conducted by (Al-alak \& Alnawas, 2011) who prove empirically a positive relationship between management support with intention in using e-Learning. Other previous studies also found that organizational support as an important antecedent of ease of use and usefulness, for example, studies of (Davis \& Warshaw, 1989) and (Igbaria, Zinatelli, Grag, \& Cavaye, 1997). In addition, a study conducted in Taiwan (Wu, Chen, \& Lin, 2007) replicated Igbaria study found that the three policies in each of these: support of the organization; management, education and training; and computer facility exert positive impact on the Intention of Using E-Learning.

\subsection{Influence of Organizational Support on Usefulness}

In terms of organizational support, Chau (2001) posits a user of an institution who has a strong belief that the organization that constantly provides resources, technical, and management supports will encourage the adoption of technology. Previous studies prove a significant relationship between management support with intention in using the system. They found that management support is a critical factor that contributes to the success of the system, for examples a study conducted by (Igbaria, Zinatelli, Grag, \& Cavaye, 1997) showed that organizational support is positively related to the perceived usefulness in using e-Learning; Sun \& Zhang (2006) prove empirically that management support has a positive influence on the perceived usefulness and ease of use of information technology. They also prove empirically that the support of top managers on the use of e-Learning training effect on the achievement of results.

However, the current study shows a positive, but little impact of organizational support on the usefulness of using e-Learning. The result suggests that the students' perceived organizational support does not affect the real usefulness of using e-Learning among students in Southeast Sulawesi province of Indonesia. Although, students' perceptions of the usefulness of using e-Learning is quite high, but the perceived usefulness of using e-Learning is not supported by the students' perceived organizational support. This is likely to be a controversial result in which prior studies support a very strong effect of management support on Intention to Use E-Learning, for examples, studies conducted by (Al-alak \& 
Alnawas, 2011) and (Chen, Wang, Murman, Olaniran, \& Chen, 2012) which prove empirically that there is a positive relationship between Perceived Organizational Support on the usefulness for using e-Learning. However, the results of the current study show that the respondents have a good perception of the usefulness of using e-Learning as it helps in accelerating the completion of the study, reducing the time span of the study period, and improving academic achievement, in spite of the fact that organizational support of their institutions is not maximized. Further studies have to be developed to seek if Organizational Support has no direct effect on Intention to use E-Learning.

\subsection{Influence of Organizational Culture on Intention on Using the E-Learning}

Several researchers have conducted studies regarding the role of organizational culture, among others, in the context of absorptive capacity and IT success study, which was conducted by (Harrington \& Guemaraes, 2005), the study of adoption and diffusion of the implementation of information technology which was conducted by (Syler, 2003). The important thing that is worth noting that organizational culture has been used in various ways in the research literature.

As expected, the result of the current study shows that organizational culture has a positive and significant impact on the intention on using e-Learning. It reflects that the better the environmental factors of organizational culture in which students are studying, then the better the perception of the desire to use the learning technology of e-Learning The results are consistent with Njenga (2011) who argues that the culture of an organization that is responsive to changes is more likely to succeed in adopting technology. Therefore, an organization which has positive reactions to changes in technology will affect its acceptance on the use of e-Learning.

\subsection{Influence of Organizational Culture on Perceived Usefulness of Using E-Learning}

Based on the analysis, organizational culture has a positive and significant effect on the perception of the usefulness of using e-Learning. It implies that the better the students' perceptions on the cultural environment of the college where they attend a course, the higher the level of their perception of the usefulness value of using e-Learning. The result also shows and gives confidence that the cultural construct can be measured and incorporated into the technology acceptance model. The result is relevant to the opinion of (Carey \& Kacmar, 2010) who suggests that culture is more important than other aspects. They proved empirically that cultural preferences significantly influence the perception of expediency. Their finding verifies that cultural differences are of paramount importance to the usefulness. This finding also reflects that the users of information systems in China put the usefulness as a critical factor.

\subsection{Influence of Ease of Use on Usefulness of Using E-Learning}

The current study indicates that there is a positive and significant influence of ease of use on the usefulness of using eLearning. This finding is in line with some of the previous studies. The previous finding, for example, shown by (Tarhini, Hone, \& Liu, 2013) empirically proves that the perceived usefulness affects the intention in using e-Learning with $p$ $<0.001$. Similarly, (Wang, Wang, Lin, \& Tang, 2003) found that the usefulness is very influential antecedent to intention to use e-Learning. The result is more important than that of perceived ease of use of e-Learning.

\subsection{Influence of Perceived Ease of Use on Intention in Using E-Learning}

The present study shows there is a positive effect of the perceived ease of use construct of e-Learning on the intention in using e-Learning. This finding implies that the higher the level of perceived ease of uses of e-Learning, the higher the intention in using e-Learning. It also suggests that in order to increase the acceptance of the use of e-Learning it is essential to increase the frequency of a workshop on the use of e-Learning. Results of previous studies, for example, conducted by Davis (1986) prove a positive influence of ease of use on intention to use a system. More than ten years later, (Wang, Wang, Lin, \& Tang, 2003) and (Amin, 2009) reported that Perceived Ease of Use exerts a significant influence on the attitudes and intentions of students use. Other prior studies were conducted by (Ong \& Lai, 2006) who found that Perceived Ease of Use has a significant effect on the intention of students using e-Learning. Also, Chau (1996) proved empirically a positive effect of Perceived Ease of Use on Intention. It is expected that students who perceive eLearning as a simple matter affects their intention in adopting the system. 


\subsection{Influence of Perception Usefulness on Intention in Using E-Learning}

The present study shows a positive and significant impact of Usefulness on the construct of Intention in using e-Learning. This finding implies that students perceive e-Learning as being beneficial which can further affect an intention of adopting e-Learning. The other relevant empirical finding is presented by (Wang, Wang, Lin, \& Tang, 2003) proves Perception of the Usefulness of Using e-Learning affects Intention on a system with a significant level of $p<0.01$. The TAM perspective theory posits a person intends to do something before he did it.

\section{Conclusions}

The main objective of this study was to examine and validate the extending of TAM with Organizational Support, Organizational Culture, and Ease of Use affecting Perceived Usefulness and Intention to Use in a context of effective eLearning implementation in higher education institutions. After having an analysis with structural equation modeling of PLS which allowing multiple relationships to be analyzed simultaneously, the result provides support for the critical roles of Organizational Support, Organizational Culture and Perceived Ease of Use in the setting of implementing e-Learning as significant determinants of the extended TAM variables.

\section{Acknowledgement}

The author gratefully acknowledged the financial support donated in the form of a doctoral research grant from the Directorate General of Higher Education of the Republic of Indonesia under the Contract Agreement Batch I: 011/Add/Ditlitabmas/2015.

\section{References}

Al-alak, B. A., \& Alnawas, I. A. (2011). Measuring the Acceptance and Adoption of E-Learning by Academic Staff. Knowledge Management \& E-Learning. An International Journal, 3(2), 201-221.

Amin, H. (2009). An analysis of online banking usage intentions: an extension of the technology acceptance model . International Journal of Business and Society, 10(1), 27-40.

BPS [Central Bureau of Statistics] Indonesia. (2014). Statistics Indonesia 2013. Jakarta: BPS Indonesia.

Brown, I. (2002). Individual and Technological Factors Affecting Perceived Ease of Use of Web-Based Learning Technologies in Developing Countries. EJICDC, 9(5), 1-15.

Carey, J. M., \& Kacmar, C. J. (2010). Cultural and Language Affects on Technology Acceptance and Attitude: Chinese Perspective. International Journal of Information Technology, 16(1), 1-19.

Chau, P. (1996). An Empirical Assessment of a Modified Technology Acceptance Model . Journal of Management Information System, 13(2), 185-203.

Chau, P. (2001). Influence of computer attitude and self-efficacy on IT usage behaviour. Journal of End User Computing, 13(1), 26-33.

Chen, B., Wang, M., Murman, J., Olaniran, B. A., \& Chen, N.-S. (2012). The effects of organizational learning environment factors on the acceptance of e-learning. Computers and Education, 58(3), 885-899.

Chen, Y.-C., Shang, R.-A., Yu Hou, A. C., \& Humaour, K. C. (2012). Organizational Alienation, Organizational Support, and Behavioural Intention to Adopt Information Systems. PACIS 2012 Proceedings. Association for Information Sysstems AIS Electrinic Library.

Chuo, Y.-H., Tsai, C.-H., Lan, Y., \& Tsai, C.-S. (2011). The effect of organizational support, self efficacy, and computer anxiety on the usage intention of e-learning system in hospital . African Journal of Business Management, 5(14), 5518-5523.

Davis, F. D. (1986). Technology acceptance models for empirically testing new end-user information systems: Theory and results. Cambridge: MIT Sloan School of Management.

Davis, F. D., Bagozzi, R. P., \& Warshaw, P. R. (1989). User acceptance of computer technology: A comparison of two theoritical models. Management Science, 15(8), 982-1002.

Elliott, M. T., \& Fu, F. Q. (2008). Consumer Acceptance of Technology Products: The Impact of Selling Tactical Approaches. Marketing Management Journal, 18(2) , 47-64.

Fishbein, M., \& Ajzen, I. (1975). Belief, attitude, intention and behavior: An introduction to theory and research . MA: Addison-Wesley.

Ghozali, I., \& Latan, H. (2012). Partial Least Squares Concepts, Techniques and Applications in Using SmartPlusPLS 2.0. Semarang: Lembaga Percetakan UNDIP.

Harju, R. R. (2007). Information Technology Acceptance in the Finnish Social and Health Care Sector Exploring the Effect of Cultural Factors. Tampera: Esa Print Tampera.

Harrington, S. J., \& Guemaraes, T. (2005). Corporate Culture, Absorptive Capacity, and IT Success. Information and Organization, 15, 39-63.

Hartwick, J., \& Barki, H. (1994). Explaining the role of user participation in information system use. Management Science, 40(4), 440- 
465.

Igbaria, M., Zinatelli, N., Grag, P., \& Cavaye, A. L. (1997). Personal computing acceptance factors in small firms. MIS Quarterly, 21(3), 279-305

King, W. R., \& He, J. (2006). A meta-analysis of the technology acceptance model. Information \& Management, 43, 740-755.

Lee, Y. (2006). An Empirical investigation into factors influencing the adoption of an e-learning system. Online Information Review, 30(5), $517-541$

Liao, H.-L., \& Liu, S.-H. (2011). The Effect of Course, System and Perception Antecedents on Adult Learner's Behaviour. Issues in Information Systems, 12(2), 223-230.

Macharia, J., \& Nyakwende, E. (2010). Vice-chancellors Influence on Academic Staff Intentions to Use Learning Management System (LMS) for Teaching andLlearning. The Journal of Language, Technology \& Entrepreneurship in Africa, 2(1), 220-230.

Masrom, M. (2007). Technology Acceptance Model and E-learning. International Conference on Education (pp. 1-10). Brunei Darussalam: Sultan Hasanal Bolkiah Institute of Education Univeristi Brunai Darussalam.

Melas, C. D., Zampetakis, L. A., Dimopolou, A., \& Moustakis, V. (2011). Modeling the acceptance of clinical information systems among hospital medical staff: An extended TAM model. Journal of Biomedical Informatics, 553-564.

Moon, J.-W., \& Kim, Y.-G. (2001). Extending the TAM for a World-Wide-Web context. Information and Management, 38, 217-230.

Njenga, J. (2011). E-learning adoption in the Eastern and Southern African higher education institutions, Dissertation. Department of Information Systems, University of Western Cape.

Ong, C.-S., \& Lai, J.-Y. (2006). Gender difference in perceptions among dominants of e-Learning acceptance. Computer in Human Behaviour, 22(5), 816-829.

Park, S. (2009). An Analysis of the Technology Acceptance Model in Understanding Univerisity Students' Behavioural Intention to Use eLearning. Educational Technology \& Society, 12(3), 150-162.

Porter, C. E., \& Donthu, N. (2006). Using the technology acceptance model to explain how attitudes determine Internet usage: The role of perceived access barriers and demographics. Business Research, 59(9), 999-1007.

Rezaei, M., Mohammadi, H. M., Asadi, A., \& Kalantary, K. (2008). Predicting E-Learning Application in Agricultural Higher Education Using Technology Acceptance Model. Turkish Online Journal of Distance Education, 98(1), 85-95.

Roca, J. C., \& Gagne, M. (2008). Understanding e-Learning continuance intention in the workplace: A self-determination theory perspective . Computers in Human Behaviour, 24(4), 1585-1604.

Saade, R. G. (2003). Web-based education information system for enhanced learning EISEL: Student assesment. Journal of Information Technology Education, 2, 267-277.

Shen, J., \& Eder, L. B. (2010). Intentions to Use Virtual Worlds for Education. Journal of Information Systems Education, 20(2), 225-233.

Solimun. (2004). Structural Equation Modeling (SEM) . Malang: Graduate Program Faculty \& UB .

Sugiyono. (2009). Quantitative Research Method and R \& D. New York: Alfabeta.

Sun, H., \& Zhang, P. (2006). Applying Markus and Robey's Causal Structure to Examine User Technology Acceptance Research: A New Approach. Journal of Information Technology Theory and Application (JITTA), 8(2), 21-4-.

Syler, R. (2003). Exploring the Fit of Organizational CultureTraits and Information Technology Infrastructure Flexibility: A Partial Least Square Approach. Auburn University.

Tanduklangi, A. (2014). Association of Organizational Support, Organizational Culture, Easeness, and Usefulness Towards Students Intention in using e-Learning. Kendari: Program Pascasarjana Universitas Halu Oleo.

Tanduklangi, A., Alberth, \& Amri, C. (2014). Teaching writing through hybrid instruction, how effective is it? International Journal of Academic Research Part B, 6(5), DOl: 10.7813/2075-4124.2014/6-5/B.21, 136-142.

Tarhini, A., Hone, K., \& Liu, X. (2013). Factors Affecting Students ' Acceptance of e-Learning Environments in Developing Countries . International Journal of Information and Education Technology, 13(1), 54-59.

Wang, Y.-S., Wang, Y.-M., Lin, H.-H., \& Tang, T.-I. (2003). Determinants of user acceptance of internet banking: an empirical study. International Journal of Service Industry Management, 14(5), 501-519.

Wu, J.-H., Chen, Y.-C., \& Lin, L.-M. (2007). An empirical study of end-user computing acceptance factors in small and medium enterprises in Taiwan: Analysed by structural equation modeling. Journal of Computer Information Systems, 23, 162-174.

Ya-Chu, Y., \& Kuo-Hung, H. (2011). An Investigation on Telecommunication Staff's Acceptance of E-Learning Technology. Journal of Modern Accounting and Auditing, 7(10), 1150-1157.

Yen, D. C., Wu, C.-S., Cheng, F.-F., \& Huang, Y.-W. (2010). Determinants of User's Intention to Adopt Wireless Technology: An Empirical Study by Integrating TTF with TAM. Computers in Human Behaviour, 28(5), 906-915. 